\title{
ASSESSMENT OF RUNWAY ACCIDENT HAZARDS IN NIGERIA AVIATION SECTOR
}

\author{
Akinyemi Olasunkanmi Oriola ${ }^{1}$, Adebiyi Kazeem Adekunle ${ }^{2}$ \\ ${ }^{1}$ Mechanical Engineering Department, Olabisi Onabanjo University, Ago-Iwoye, Nigeria \\ ${ }^{2}$ Mechanical Engineering Department, Ladoke Akintola University of Technology, Ogbomoso, Nigeria
}

Received 5 September 2014; accepted 19 December 2014

\begin{abstract}
Aviation crashes all over the world have recently been on the high rise, stemming from negligence, mechanical faults, weather, ground control errors, pilot errors, taxing and maintenance crew errors as probable reasons for such accidents. This study models the probabilistic risk assessment of runway accident hazards in Nigeria aviation sector. Six categories of runway accident hazards with their corresponding basic events were identified and modeled using fault tree analysis method of probabilistic risk assessment. The six categories of runway accident hazards are runway surface conditions, weather conditions, collision risk, aircraft system failure, approach/takeoff procedures and human factors. The Fault Tree developed is a system of OR-gates and the weights for each hazard were derived through a domain/expert opinion. The estimated probability of occurrence of runway accident which is the top event of the Fault Tree model is 0.2624. Fault Tree Analysis; thus, identifies the most likely root causes of runway accident through importance measures. The results of the analysis show close relationship of runway accidents in Nigeria aviation sector with aircraft system failure, approach/takeoff procedures, human factor, weather conditions and collision risk.
\end{abstract}

Keywords: runway accident, runway surface condition, aircraft system failure, approach/ takeoff procedures, human factors.

\section{Introduction}

The ever increasing growth in air transport implies increasing demand for air transport services, which further propagates into need for providing more efficient, effective and safe runway operations. Landing and take-off are critical phases of flight operations and runway is an area where landing and departing aircraft may have the opportunities to interact with other taxiing aircraft, ground vehicles, personnel, animals and foreign objects. Given the speed of aircraft and its limited ability in exercising avoiding actions on the runway especially during take-off and landing roll, the potential hazard as may be created by runway accidents have become a deep concern to aviation safety in many countries.
The worst aircraft accident in aviation history happened in 1977 and it was a runway collision involving two Boeing 747 aircraft in Tenerife, the Canary Islands, resulting in the loss of 583 persons. International Civil Aviation Organization (ICAO) has specified Standards and Recommended Practices (SARPs) relating to airport system operation and the development of operational procedures for the purpose of achieving runway safety. Despite all these efforts, absolute aviation safety for humans and property is still a mirage and unsafe events still persist. Aviation accident and prevention have been challenging within the air transportation industry for years and undoubtedly will continue to be a major concern for not only aviation professionals

\footnotetext{
${ }^{1}$ Corresponding author: aooakinyemi@oouagoiwoye.edu.ng
} 
but for all those directly or indirectly affected by air transportation. Accordingly, although safety conditions are exceptionally good in air transport, as compared with rail, road and water transport, safety management is a fundamental factor for the sustainability of this service (Pacheco et al., 2014).

Runway accidents are majorly runway incursions and runway excursions. A runway incursion is any unauthorized intrusion onto a runway, regardless of whether or not an aircraft presents a potential conflict (US Federal Administration Authority, 2008b). Runway incursions have sometimes led to serious accidents with significant loss of life. Although runway incursion is not a new problem, with increasing air traffic, runway incursions have been on the rise. According to the US internal FAA documents, as of September 4, 2008, there were 921 runway incursions in Fiscal Year, FY2008, 106 more than during the same period in FY2007. Runway incursions have also exceeded the limit placed by Federal Administration Authority (FAA) performance standards, which allows not more than 769 runway incursions during the entire fiscal year (US Federal Administration Authority, 2008b). Of all the runway incursions that occurred in FY 2007, 57 percent were caused by pilots, 28 percent by controllers and 15 percent by ground vehicles. At the end of FY2008, 1009 runway incursion was recorded; the highest in last couple of years 779 in FY 2005, 816 in FY 2006 and 892 in FY 2007. In FY 2009, the number of runway incursion decreased by 13 percent to 951 . It should be noted that there were $52,928,316$ surface operations in 2009 as against 58, 560, 343 surface operations in 2008. The decrease in runway incursions should be expected due to decreased in surface operations in 2009. In FY2012, 583 towered airports reported a total of 1,150 runway incursion, which is an increase from 954 runway incursion in FY 2011 and 966 runway incursions in FY 2010 (US Federal Administration Authority, 2012).

Aviation safety programme has a common goal - to reduce hazards and manage residual risk in air transportation. Runway operations are an integral part of aviation; the hazards and risks associated with runway operations need to be managed in order to prevent runway incursions that may lead to accidents. According to the Manual on the Prevention of Runway Incursions (International Civil Aviation Organization, 2007), a number of factors is likely to be responsible for the continuing increase in runway incursions, including traffic volume, capacity-enhancing procedures, aerodrome design and increasing environmental pressures. These factors, combined with inadequate training, poor infrastructure and system design, and inadequate ATC facilities, can lead to an increased risk of runway incursions.

On the other hand, runway excursions include events of two types: veer-offs, in which an aircraft goes off the side of a runway, and overruns, in which an aircraft runs off the end of a runway (US Federal Administration Authority, 2008a). Runway excursion comprises $96 \%$ of all runway accidents; $80 \%$ of fatal runway accidents and $75 \%$ of related fatalities. Nevertheless, although these accidents have been the subject of a few studies, the number has been relatively small and the recommended preventive measures have been relatively few compared with numerous programmes devoted to runway incursions (Kirkland et al., 2004; Werfelman, 2008). Runway excursion accidents are not rare events, many do not involve much damage and 
there may be no injuries but many are serious and involve substantial damage, and a few are deadly. In most instances, a runway excursion is not a total surprise to the flight crew. The severity of runway excursion accidents depends primarily on the energy of the aircraft as it departs the runway and the airport layout, geography and rescue capabilities. However, a major factor is whether the crew has flown a stabilized approach. The ability and tendency to achieve the recommended elements of a stabilized approach is inherent in human factors. Conversely, a major factor in risk reduction is a stabilized approach with a launching in the touchdown zone, but other factors including speed, use of brakes and reverse thrust, and runway conditions are contributing factors.

For years, any discussion of runway accident has emphasized runway incursions. Prominent among published works in this area include those of Christoph et al. (2008); Eggert et al. (2006); Luxhøj (2003), Luxhøj et al. (2006); Rankin (2006); Scarborough et al. (2003); Scarborough et al. (2008); Stroeve et al. (2006); Ting (2007); Williams (2008) and Yong and Wang (2001). These works have extensively discussed the human factors' contribution to runway incursion, risk assessment and performance evaluation of capacity enhancing technologies. Data have also shown that efforts are being effective in preventing runway incursion, but the number of incidents and their severity still indicates a very high risk.

Several high-profile accidents between 2005 and 2013 have brought the issue of runway excursions and incursions to the forefront of Nigerian aviation safety. Most runway accidents hazards are dormant or potential, with only a theoretical risk of harm; however, once a hazard becomes "active", it can create an emergency situation. The many common cause of aircraft accidents and other aviation accidents are:

1. Maintenance negligence: A leading trend in the aviation industry is to cut corners and outsource aircraft maintenance and inspections. Airlines do the absolute minimum to keep planes in the air; as a result, crash victims and their families suffer.

2. Design defects: Components of aircrafts must be designed to withstand wind, take off, landing and the stresses of flight. When the aircraft design is inadequate, design engineers should be held accountable. We represented clients in a helicopter crash accident in which the metal in the yoke of the helicopter was not strong enough to withstand even normal wind conditions, resulting in separation from the tail rotor.

3. Crew negligence/human factors: Crew negligence often leads to aviation accidents. Another example is a case of Baum Hedland involving a Chinese Eastern Airline flight to Los Angeles. While flying over Alaska, the nose of the plane pitched straight down when the co-pilot mistakenly bumped an exposed lever that was to be kept under a dome glass cover. All unbuckled passengers hit the ceiling and suffered neck injuries some even died. While this accident is a clear example of a design defect, it is also an example of crew errors that lead to mass disasters.

4. Corporate negligence: The corporate airline industry is emphasizing timing, turnaround and cutting corners over public safety. Pilots and crew are being pushed by corporate policies to make unsafe landings to avoid paperwork, to 
fly with the minimum amount of fuel, and to make other unsafe judgment calls.

Probabilistic risk assessment (PRA) has emerged as an increasingly popular analysis tool, especially, during the last decade. PRA is a systematic and comprehensive methodology to evaluate risks associated with every life-cycle aspect of a complex engineered technological entity (e.g., facility, spacecraft, or power plant) from concept definition, through design, construction and operation, and up to removal from service. PRA methods include Event Tree Analysis, Fault Tree Analysis, Failure Mode Effect Analysis, Common Cause Failure Analysis etc.

This research aims at identifying runway accident hazards using the probabilistic risk assessment approach and subsequently determining the probability of occurrence of runway accidents.

\section{Identification of Runway Accident Hazard Events}

It should be noted that hazards lead to accidents and can occur usually due to several causes. Typically, hazards that can occur in relation to runway operations include but are not limited to the following:

\footnotetext{
a. An aeroplane arriving/departing the runway.

b. An aircraft colliding with another aircraft, vehicle, pedestrian, or bird/ wildlife on the runway.
c. Foreign object damage, FOD (to engine or other parts of the aircraft).

d. Vehicle colliding with an aircraft in the movement area (typically on the apron).

e. An aircraft colliding with obstacle during approach, low over-flight or climb-out.

f. An aircrew being misled by lights which may cause confusion or endanger the safety of aircraft.

After extensive review of previous and related works and interviews with Federal Aviation Authority, Nigeria (FAAN) and Nigeria Airspace Management Agency (NAMA) safety personnel, it was observed that human factors, deficiency in maintenance of facilities and infrastructures, increase air traffic density/volume, weather and the airfield design/environment contributed to runway accident hazards in Nigeria. Runway accidents (incursion and excursion) have a variety of causes and are often the result of a combination of factors. Causes and factors of runway accident have been identified and modelled on a Fault Trees (Figs. 1 and 2). It should be noted that fifty-nine (59) major runway incidents and accidents were experienced within the period 2000-2011 in the Nigeria aviation sector. Forty-four causes of runway accident were identified and these causes were divided into six categories, representing minimal cut sets of the Fault Tree (FT) developed. These categories are stated as follows:

1. Human error,

2. Runway surface condition,

3. Collision,

4. Weather condition,

5. Approach/Take-off procedure, and

6. Aircraft system failure. 


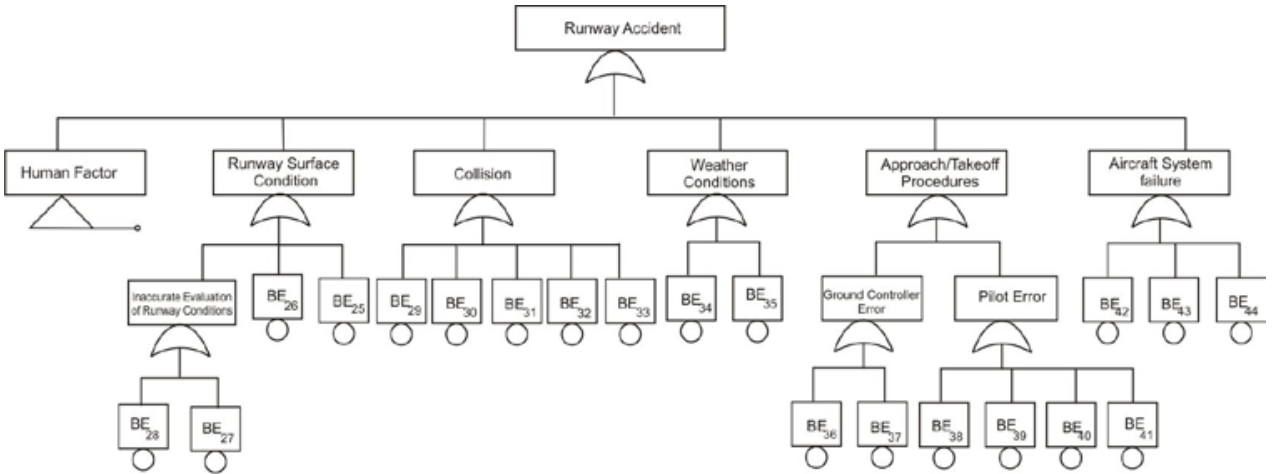

Fig. 1.

Fault Tree Diagram for Estimating the Probability of Runway Accident Occurrence

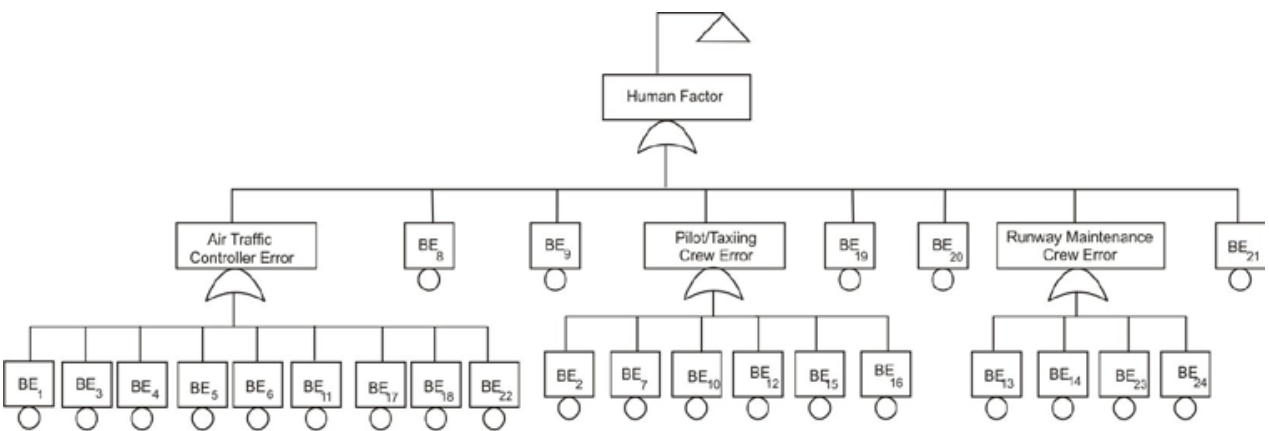

Fig. 2.

Fault Tree Diagram for Human Factor Intermediate Event

Several causes within each of these categories may be present during runway accidents and incidents. The majorities of these causes were taken from the list of casual and contributing factors described in the investigation reports while those that are not listed in the report were identified and included in the Fault Tree Analysis (FTA). The complete list of casual (basic) events within each category is shown in Table 1 . 


\section{Table 1}

Casual (Basic) Events during Runway Accidents

\begin{tabular}{|c|c|c|}
\hline $\mathbf{S} / \mathbf{N}$ & Categories(MCS) & Casual (basic) events \\
\hline 1. & Human Error (HE) & $\begin{array}{l}\text { Ground control untimely intervention } \\
\text { Pilot loss of situation awareness } \\
\text { Departure runway not verified prior to take off } \\
\text { Communication loss between Ground Control and Taxing crew } \\
\text { No condition monitoring of aircraft during taxing } \\
\text { Delay in information sharing between Ground Control and other runaway users. } \\
\text { Work pressure on pilot } \\
\text { Level experience in situation management } \\
\text { Yieldness to training on prevailing condition } \\
\text { Negligence of safety signal marking by taxing crew } \\
\text { Use of non-standard signals } \\
\text { Lack of coordination between taxing crew } \\
\text { Delay in runway condition information sharing to appropriate quarters } \\
\text { Loss of situation awareness by maintenance crew } \\
\text { Indecisiveness of pilot to act } \\
\text { Poor crisis management by pilot } \\
\text { Emergency response of departure controller } \\
\text { Momentary confusion clearance issued } \\
\text { Working condition of airline and airport } \\
\text { Flight engineer error in data not corresponding to prevailing runway condition } \\
\text { Error in weather reportage and weather data analysis } \\
\text { Runway allocation error due to incorrect runway assignment and data upload } \\
\text { Runway maintenance crew negligence } \\
\text { Use of ambiguous terms to describe prevailing condition }\end{array}$ \\
\hline
\end{tabular}

2. Runway Surface Condition Limitation of aquaplaning

Lack of appropriate runway condition description: Wet/Contamination/Low

friction: standing water, rubber, oil, slush, snow, ice, paint

Runway surface measurement device error, parallax error

Runway surface tolerance error of measuring device

3. Collision

Bird strike

Other wild life strike

Wrong diversion/sign and markings

No diversion/sign and markings

Loss of require separation

4. Weather condition

Low visibility

Wind shear

Tail wind

Gusts

Low ceiling

Strong winds

Turbulence

Freezing rain

Rain

5. Approach/Take off

Delay in order to abort a takeoff having seen an obstacle

Procedures

Take-off rejected at high speed

Defaulting SOP (standard operating procedure)

Long touch-down zone/high speed during approach

Approach below flight path

Approach above flight path

Pilot error in over-speeding (high speed and/or low speed)

6. Aircraft system failure

Un-optional wheel braking force/brake

Tires

Hydraulic

Power 


\section{Fault Tree Analysis for Estimating Probability of Occurrence of Runway Accident}

The fault tree developed is a system of OR-gates for all connection of events. The top event (runway accident) occurs if at least one of the minimal cut sets occurs. The expert/domain opinion was used to estimate the probability of basic events of the minimal cut sets. A set of questionnaire was developed and given to respondents in Nigeria Civil Aviation Authority (NCAA), Nigeria Airspace Management Agency (NAMA), Federal Aviation Authority in Nigeria (FAAN) and Accident Investigation Bureau. The estimates of weight of causal basic events are presented in Table 2 .

Table 2

Weight of Basic Events and their Description

\begin{tabular}{|c|c|c|c|}
\hline $\mathbf{S} / \mathbf{N}$ & ID & Description of event & Probability \\
\hline 1 & BE1 & Ground controls untimely intervention & 0.003 \\
\hline 2 & BE2 & Pilot loss of situation awareness & 0.0055 \\
\hline 3 & BE3 & Departure runway not verified prior to take off & 0.006 \\
\hline 4 & BE4 & Communication loss between Ground Control and Taxing crew & 0.0055 \\
\hline 5 & BE5 & No condition monitoring of aircraft during taxing & 0.0033 \\
\hline 6 & BE6 & Delay in information sharing between Ground Control and other runway users. & 0.0055 \\
\hline 7 & BE7 & Work pressure on pilot & 0.0055 \\
\hline 8 & BE8 & Level experience in situation management & 0.0043 \\
\hline 9 & BE9 & Yieldness to training on prevailing condition & 0.0055 \\
\hline 10 & BE10 & Negligence of safety signal marking by taxing crew & 0.006 \\
\hline 11 & BE11 & Use of non-standard signals & 0.006 \\
\hline 12 & $\mathrm{BE} 12$ & Lack of coordination between taxing crew & 0.0043 \\
\hline 13 & BE13 & Delay in runway condition information sharing to appropriate quarters & 0.0055 \\
\hline 14 & BE14 & Loss of situation awareness by maintenance crew & 0.0055 \\
\hline 15 & $\mathrm{BE} 15$ & Indecisiveness of pilot to act & 0.003 \\
\hline 16 & BE16 & Poor crisis management by pilot & 0.003 \\
\hline 17 & BE17 & Emergency response of departure controller & 0.0055 \\
\hline 18 & BE18 & Momentary confusion of clearance issued & 0.0033 \\
\hline 19 & BE19 & Working condition of airline and airport & 0.0025 \\
\hline 20 & $\mathrm{BE} 20$ & Flight engineer error in data not corresponding to prevailing runway condition & 0.006 \\
\hline 21 & $\mathrm{BE} 21$ & Error in weather reportage and weather data analysis & 0.0085 \\
\hline 22 & $\mathrm{BE} 22$ & Runway allocation error due to incorrect runway assignment and data upload & 0.0085 \\
\hline 23 & BE23 & Runway maintenance crew negligence & 0.006 \\
\hline 24 & BE24 & Use of ambiguous terms to describe prevailing condition & 0.0035 \\
\hline 25 & $\mathrm{BE} 25$ & Limitation of aqua-planning & 0.006 \\
\hline 26 & BE26 & $\begin{array}{l}\text { Lack of appropriate runway condition description: Wet/Contamination/Low friction: } \\
\text { standing water, rubber, oil, slush, snow, ice, paint }\end{array}$ & 0.0036 \\
\hline 27 & $\mathrm{BE} 27$ & Runway surface measurement device error, parallax error & 0.006 \\
\hline 28 & $\mathrm{BE} 28$ & Runway surface tolerance error of measuring device & 0.0035 \\
\hline 29 & $\mathrm{BE} 29$ & Bird strike & 0.005 \\
\hline 30 & BE30 & Other wild life strike & 0.008 \\
\hline 31 & BE31 & Wrong diversion/sign and markings & 0.0035 \\
\hline 32 & $\mathrm{BE} 32$ & No diversion/sign and markings & 0.0085 \\
\hline 33 & BE33 & Loss of required separation & 0.0085 \\
\hline 34 & BE34 & Low visibility, Low ceiling & 0.0085 \\
\hline 35 & $\mathrm{BE} 35$ & Wind shear, Tail wind, Strong wind, Freezing rain, Turbulence & 0.0035 \\
\hline 36 & $\mathrm{BE} 36$ & Delay in order to abort a take-off having seen an obstacle & 0.0055 \\
\hline 37 & $\mathrm{BE} 37$ & Take off rejected at high speed & 0.006 \\
\hline 38 & $\mathrm{BE} 38$ & Defaulting SOP (Standard operating procedure) & 0.009 \\
\hline 39 & BE39 & Long touch-down zone/high speed during approach & 0.009 \\
\hline 40 & BE40 & Approach below flight path, Approach above flight path & 0.006 \\
\hline 41 & BE41 & Pilot error in over-speeding (high speed and/or low speed) & 0.0035 \\
\hline 42 & BE42 & Un-optional wheel braking force/brake & 0.009 \\
\hline 43 & BE43 & Tires & 0.009 \\
\hline 44 & BE44 & Hydraulic Power & 0.005 \\
\hline
\end{tabular}


Probability of runway accident;

$$
\begin{gathered}
\text { Prob }(\text { RWY ACC })=1-\prod_{i=1}^{44}\left(1-B E_{i}\right)(1) \\
=1-(1-0.003) \times(1-0.0095) \times(1-0.0085) \times(1-0.0055) \times(1-0.0055) \times(1-0.0055) \times(1-0.0085) \\
\times(1-0.0045) \times(1-0.0055) \times(1-0.008) \times(1-0.006) \times(1-0.0045) \times(1-0.0055) \\
\times(1-0.0085) \times(1-0.003) \times(1-0.003) \times(1-0.0055) \times(1-0.0033) \times(1-0.0025) \\
\times(1-0.005) \times(1-0.0085) \times(1-0.0085) \times(1-0.0085) \times(1-0.0035) \times(1-0.009) \\
\times(1-0.0085) \times(1-0.006) \times(1-0.0035) \times(1-0.005) \times(1-0.008) \times(1-0.0035) \times(1 \\
-0.0085) \times(1-0.0085) \times(1-0.0085) \times(1-0.0035)) \times(1-0.0055) \times(1-0.006) \times(1 \\
-0.009) \times(1-0.009) \times(1-0.006) \times(1-0.0035) \times(1-0.009) \times(1-0 . .9) \times(1-0.005) \\
\text { Prob }(\text { RWY ACC })=0.262357463 \\
\text { Prob }(\text { RWY ACC } \cong 0.2624
\end{gathered}
$$

The quantitative analysis has successfully captured all causal elements in the event of runway accident with a probability of 0.2624 chance of occurrence.

Kim and Yang (2012) described the Fault Tree importance measures and how they can help in decision making. Importance measures used in this study were FussellVesley (FV) and risk reduction worth (RRW). The importance results for each basic event are shown in Table 3. The event with the greatest contribution to runway accident for system unavailability is the working condition of airline and airport, followed by ground controllers untimely intervention, no condition monitoring of aircraft during taxing, indecisiveness of pilot to act, poor crisis management by pilot, momentary confusion of clearance issued, runway surface tolerance error of measuring device, use of ambiguous terms to describe prevailing condition, wrong diversion/sign and markings, wind shear, tail wind, strong wind, freezing rain, turbulence and Pilot error in over-speeding (high speed and/or low speed). The events with the lowest contribution are defaulting SOP, long touch-down zone/high speed during approach, un-optional wheel braking force/brake and aircraft tires. The $\mathrm{FV}$, which represents the contribution of the hazard to systematic risk, shows that working condition of airline and airport, followed by ground controllers untimely intervention, no condition monitoring of aircraft during taxing, indecisiveness of pilot to act, poor crisis management by pilot, momentary confusion of clearance issued, runway surface tolerance error of measuring device, use of ambiguous terms to describe prevailing condition, wrong diversion/sign and markings, wind shear, tail wind, strong wind, freezing rain, turbulence and Pilot error in over-speeding (high speed and/ or low speed) contributed more to system risk. However, the importance of the lowest contributing runway accident hazards with 28.48 was only about $1 / 4^{\text {th }}$ of the greatest hazard.

RRW, which seeks to determine the best solution for solving the system's hazards, has the same result as that of FV. The most important hazards are working condition of airline and airport, followed by ground controllers untimely intervention, no condition monitoring of aircraft during taxing, indecisiveness of pilot to act, poor crisis management by pilot, momentary confusion of clearance issued, runway surface tolerance error of measuring device, use of ambiguous terms to describe prevailing condition, wrong diversion/sign and markings, wind shear, tail wind, strong wind, freezing rain, turbulence and Pilot error in over-speeding (high speed and/or 
low speed). These runway accident hazards are given priority over the others for reducing runway accidents in the Nigerian aviation sector. In addition, the hazards estimated with relatively high RRW are mostly related to human factors.

\section{Table 3}

Results of Importance Analyses

\begin{tabular}{|c|c|c|c|c|}
\hline $\mathbf{S} / \mathbf{N}$ & Basic event & Probability of occurrence of runway accident hazards & $\mathbf{F V}=\boldsymbol{F}^{o} / \boldsymbol{F}^{i}$ & $R R W=1-1 / F V$ \\
\hline 1 & BE19 & 0.0025 & 104.96 & 0.9905 \\
\hline 2 & BE1 & 0.003 & 87.47 & 0.9886 \\
\hline 3 & BE15 & 0.003 & 87.47 & 0.9886 \\
\hline 4 & BE16 & 0.003 & 87.47 & 0.9886 \\
\hline 5 & BE5 & 0.0033 & 79.52 & 0.9874 \\
\hline 6 & BE18 & 0.0033 & 79.52 & 0.9874 \\
\hline 7 & BE28 & 0.0035 & 74.97 & 0.9867 \\
\hline 8 & BE24 & 0.0035 & 74.97 & 0.9867 \\
\hline 9 & BE31 & 0.0035 & 74.97 & 0.9867 \\
\hline 10 & BE35 & 0.0035 & 74.97 & 0.9867 \\
\hline 11 & BE41 & 0.0035 & 74.97 & 0.9867 \\
\hline 12 & BE26 & 0.0036 & 72.89 & 0.9863 \\
\hline 13 & BE8 & 0.0043 & 61.02 & 0.9836 \\
\hline 14 & BE12 & 0.0043 & 61.02 & 0.9836 \\
\hline 15 & BE29 & 0.005 & 52.48 & 0.9809 \\
\hline 16 & BE44 & 0.005 & 52.48 & 0.9809 \\
\hline 17 & BE2 & 0.0055 & 47.71 & 0.9790 \\
\hline 18 & BE4 & 0.0055 & 47.71 & 0.9790 \\
\hline 19 & BE6 & 0.0055 & 47.71 & 0.9790 \\
\hline 20 & BE7 & 0.0055 & 47.71 & 0.9790 \\
\hline 21 & BE9 & 0.0055 & 47.71 & 0.9790 \\
\hline 22 & BE13 & 0.0055 & 47.71 & 0.9790 \\
\hline 23 & BE14 & 0.0055 & 47.71 & 0.9790 \\
\hline 24 & BE17 & 0.0055 & 47.71 & 0.9790 \\
\hline 25 & BE36 & 0.0055 & 47.71 & 0.9790 \\
\hline 26 & BE3 & 0.006 & 43.73 & 0.9771 \\
\hline 27 & BE10 & 0.006 & 43.73 & 0.9771 \\
\hline 28 & BE11 & 0.006 & 43.73 & 0.9771 \\
\hline 29 & BE20 & 0.006 & 43.73 & 0.9771 \\
\hline 30 & BE23 & 0.006 & 43.73 & 0.9771 \\
\hline 31 & $\mathrm{BE} 25$ & 0.006 & 43.73 & 0.9771 \\
\hline 32 & $\mathrm{BE} 27$ & 0.006 & 43.73 & 0.9771 \\
\hline 33 & BE37 & 0.006 & 43.73 & 0.9771 \\
\hline 34 & BE40 & 0.006 & 43.73 & 0.9771 \\
\hline 35 & BE30 & 0.008 & 32.80 & 0.9695 \\
\hline 36 & $\mathrm{BE} 21$ & 0.0085 & 30.87 & 0.9676 \\
\hline 37 & BE22 & 0.0085 & 30.87 & 0.9676 \\
\hline 38 & BE32 & 0.0085 & 30.87 & 0.9676 \\
\hline 39 & BE33 & 0.0085 & 30.87 & 0.9676 \\
\hline 40 & BE34 & 0.0085 & 30.87 & 0.9676 \\
\hline 41 & BE38 & 0.009 & 29.16 & 0.9657 \\
\hline 42 & BE39 & 0.009 & 29.16 & 0.9657 \\
\hline 43 & $\mathrm{BE} 42$ & 0.009 & 29.16 & 0.9657 \\
\hline 44 & BE43 & 0.009 & 29.16 & 0.9657 \\
\hline
\end{tabular}




\section{Conclusion}

This paper identified runway accident hazards in Nigeria aviation sector, which experienced fifty-nine (59) major runway incidents and accidents within the period 2000-2011. Forty-four (44) runway accident hazards being identified and their weights were evaluated based on experts/ domain opinion. Using these runway accident hazards, FTA was conducted. The hazard found to be linked with the highest risk of occurrence of runway accident are; working condition of airline and airport, followed by ground controllers untimely intervention, no condition monitoring of aircraft during taxing, indecisiveness of pilot to act, poor crisis management by pilot, momentary confusion of clearance issued, runway surface tolerance error of measuring device, use of ambiguous terms to describe prevailing condition, wrong diversion/signs and markings, wind shear, tail wind, strong wind, freezing rain, turbulence and Pilot error in over-speeding (high speed and/or low speed). The runway accident hazards with the lowest risk of occurrence of runway accident are defaulting SOP, long touch-down zone/ high speed during approach, un-optional wheel braking force/brake and aircraft tires.

The probability of occurrence of runway accident was 0.2624 . Risk importance measures of FTA namely Fussell-Vesley and RRW were used to rank the contribution of each runway accident hazards to the occurrence of runway accident. The research has pointed out areas of concentration for aviation authorities for effective runway safety programme.

\section{References}

Christoph, V.; Carole, U.; Uwe, K. 2008. Simulator evaluation of novel surface movement awareness and alerting system (SMAAS) for runway incursion avoidance. In Proceedings of the 26th Congress of International Council of the Aeronautical Sciences (ICAS), Anchorage, Alaska.

Eggert, J.R.; Howes, B.R.; Kuffner, M.P.; Wilhelmsen, H.; Bernays, D.J. 2006. Operational evaluation of runway status lights, Lincoln Laboratory Journal, 16(1): 123-146.

Federal Administration Authority. 2008a. Analysis of Aircraft Overruns and Undershoots for Runway Safety Areas. Airport Cooperative Research Programme (ACRP) Report 3.

Federal Administration Authority. 2008b. Runway Safety Report: 2011-2012. US Department of Transportation, Federal Aviation Administration.

Federal Administration Authority. 2012. Runway Safety Report: Trends and Initiatives at US Towered Airports, FY2004 through FY2007. Federal Aviation Administration.

International Civil Aviation Organization. 2007. Manual on the Prevention of Runway Incursions. Doc 9870 AN/463, First Edition.

Kim, D.; Yang, H. 2012. Evaluation of the risk frequency for hazards of runway incursion in Korea, Journal of Air Transport Management. DOI: http://dx.doi. org/10.1016/j.jairtraman.2012.01.011, 23(2012): 31-35.

Kirkland, I.D.L.; Caves, R.E.; Humphreys, I.M.; Pitfield, D.E.; 2004. An Improved methodology for assessing risk in aircraft operations at airports applied to runway overruns, Safety Science. DOI: http://dx.doi. org/10.1016/j.ssci.2004.04.002, 42(10): 891-905.

\section{jitte 91}


Luxhøj,J.T. 2003. Probabilistic causal Analysis for System Safety Risk Assessments in commercial Transport. In Proceedings of the second workshop on the investigation and reporting of incidents and Accident (IRIA), 17-38.

Luxhøj, J.T.; Jalil, M.; Jones, S.M. 2006. A risk based decision support tool for evaluating aviation technology integration in the national airspace system. In Proceeding of the AIAA'S 3rd Annual Aviation Technology, Integration and Operation (ATIO) Technical Forum, Denver, Colorado, November 17-19.

Pacheco, R.R.; Fernandes, E.; Domingos, E.M. 2014. Airport airside safety index, Journal of Air Transport Management. DOI: http://dx.doi.org/10.1016/j. jairtraman.2013.08.007, 34(2014): 86-92.

Rankin, W.B. 2006. Runway Incursions: A critical examination of Airport driver training methods. $\mathrm{PhD}$ thesis submitted to the Department of Business and Technology Management, North Central University, Prescott, Arizona.

Scarborough, A.; Pounds, J.; Bailey, L. 2003. Human factors classification of runway incursion associated with V/PD. FAA Civil Aeromedical Institute, Oklahoma City.
Scarborough, A.; Pounds, J.; Bailey, L. 2008. Analysing Vehicle operator deviations. FAA Civil Aeromedical Institute, Oklahoma City.

Stroeve, S.; Blom, H.; Bakker, B. 2006. Safety risk impact analysis of an ATC runway incursion alert system. National Aerospace laboratory. EUROCONTROL safety R\&D seminar, Barcelona, Spain.

Ting, K-P. 2007. The effectiveness of surface movement radar in the prevention of runway incursions: A case study. M.Sc. thesis submitted to the Department of Air Transport, Cranfield University.

Werfelman, L. 2008. Safety on the straight and narrow flight. Flight Safety Foundation. Available from Internet: $<$ http://www.flightsafety.org >.

Williams, P. 2008. Runway Incursions: A review based on Transport Accident investigation commission report 07-005. Australia and New Zealand Societies of Air Safety Investigators Annual Seminar.

Yong, K.; Wang, T. 2001. Human Factors analysis and methodology of the SQ006 accident. In Proceedings of Aviation Safety Council of Taiwan. 